\title{
The Continuous Mutual Evolution of Equatorial Waves and the Quasi-Biennial Oscillation of Zonal Flow in the Equatorial Stratosphere*
}

\author{
MING CAI \\ Department of Earth, Ocean and Atmospheric Science, Florida State University, Tallahassee, Florida \\ CORY BARTON \\ Department of Earth, Ocean and Atmospheric Science, and Geophysical Fluid Dynamics Institute, Florida State \\ University, Tallahassee, Florida \\ CHUL-SU SHIN \\ Center for Ocean-Land-Atmosphere Studies, George Mason University, Fairfax, Virginia \\ JEFFREY M. CHAGNON \\ Department of Earth, Ocean and Atmospheric Science, Florida State University, Tallahassee, Florida
}

(Manuscript received 28 February 2014, in final form 14 April 2014)

\begin{abstract}
The continuous mutual evolution of equatorial waves and the background quasi-biennial oscillation (QBO) is demonstrated using daily NCEP-U.S. Department of Energy (DOE) reanalysis for the period from 1 January 1979 to 31 December 2010. Using a novel diagnostic technique, the phase speed, vertical tilting, and form stress of equatorial waves in the stratosphere are obtained continuously on a daily basis. The results indicate that, on top of a weak-amplitude annual-cycle signal, all of these wave properties have a pronounced QBO signal with a downward propagation that evolves continuously together with the background QBO. The analysis also highlights the potential role of wave-induced form stress in driving the QBO regime change.

Dominant waves in the equatorial stratosphere propagate very slowly relative to the ground at all times, implying that their observed intrinsic phase speed evolution follows the background QBO nearly exactly but with opposite sign, as the established theory predicts. By revealing the continuous evolution of the form stress associated with the vertically tilted waves, the new diagnostic method also demonstrates the dominance of eastward-tilted, eastward-propagating waves contributing to a deceleration of easterly flow at high altitudes, which causes a downward propagation of the easterly flow signal. Similarly, the dominance of westward-tilted, westward-propagating waves acts to reverse westerly flow to easterly flow and causes a downward propagation of westerly flow signal. The results suggest that in addition to the wave-breaking processes, such continuously alternating downward transfer of westerly and easterly angular momentum by westward-tilted, westwardpropagating waves and eastward-tilted, eastward-propagating waves contributes to the wave-mean flow interaction mechanism for the QBO.
\end{abstract}

\footnotetext{
* Supplemental information related to this paper is available at the Journals Online website: http://dx.doi.org/10.1175/JAS-D-140032.s1.

Corresponding author address: Dr. Ming Cai, Department of Earth, Ocean and Atmospheric Science, Florida State University, 1017 Academic Way, Tallahassee, FL 32306.

E-mail: mcai@fsu.edu
}

\section{Introduction}

The quasi-biennial oscillation (QBO) is an alternating pattern of downward-propagating easterly and westerly wind regimes in the equatorial stratosphere with an average period of about 28 months, as originally discovered independently by Reed et al. (1961) and Veryard and Ebdon (1961). Lindzen and Holton (1968) developed the prevailing wave-mean flow interaction 
theory on this alternating regime descent phenomenon, which was further refined in Holton and Lindzen (1972) and supported by the laboratory experiment of Plumb and McEwan (1978). The gravity waves included in Lindzen and Holton's model of the QBO are (mixed) Rossby-gravity waves and equatorial Kelvin waves, which are found in observations when the background flow is westerly (Yanai and Maruyama 1966) and easterly (Wallace and Kousky 1968a,b), respectively. Two important dynamical processes of their theory are (i) those waves propagating along the same direction of the background flow cannot propagate vertically passing through their critical levels where the momentum carried by them gets deposited that causes the downward propagation of the same flow regime and (ii) those waves propagating along the opposite direction of the background flow can propagate vertically with little momentum deposition until they dissipate radiatively or mechanically where the momentum carried by them gets deposited that reverses the background flow [see Andrews et al. (1987) and Baldwin et al. (2001) for comprehensive reviews].

In the literature, time-mean properties of the dominant waves in each regime of the QBO cycle are examined via statistical methods, such as composite and spectral analysis (Tindall et al. 2006a,b; Yang et al. 2011) or windowed spectral analysis (Alexander et al. 2008; Ern et al. 2008). To the authors' knowledge, the continuous mutual evolution of equatorial waves and the QBO has not been examined from instantaneous fields, although the continuous evolution of the wave drag that drives the QBO has been analyzed (Ern and Preusse 2009; Ern et al. 2014). The purpose of this short paper is to demonstrate the temporally continuous evolution of phase speed, wavelength, vertical tilting, and associated form stress of the dominant waves in equatorial stratosphere using the daily National Centers for Environmental Prediction-U.S. Department of Energy (NCEPDOE) reanalysis dataset. This allows us to examine if and how these wave properties change continuously as the background QBO evolves in time. Additionally, we wish to explore possible contributions from these waves that can freely propagate vertically to the wave-mean flow interaction mechanism for the QBO through the form stress.
As pointed out by Lindzen and Tsay (1975), Kelvin and Rossby-gravity waves alone are inadequate to drive the observed QBO and smaller-scale gravity waves, including subgrid-scale waves, may provide the remainder. Contribution of momentum deposition from a broad spectrum of small-scale gravity waves to the QBO is at least as large as that of larger-scale equatorial waves (Dunkerton 1997; Giorgetta et al. 2002, 2006). The effects of these small-scale waves on the QBO need to be parameterized since most analysis datasets are too coarse to resolve them. Because the goal of our study is not to account for all source-sink terms for the QBO, a coarse-resolution dataset should be adequate for diagnosing wave properties of resolved waves as long as the dominant wave scales are much longer than the spatial resolution of the data (as will be shown in Fig. 2).

\section{Data and methods}

The data used in this study are derived from the daily NCEP-DOE reanalysis II (Kanamitsu et al. 2002) for the period from 1 January 1979 to 31 December 2010. We obtain pressure $p$, geopotential height $z$, temperature $T$, and zonal wind $u$ on $2.5^{\circ} \times 2.5^{\circ}$ grids at isentropic levels of $450,500,550,600,650$, and $800 \mathrm{~K}$ from their spectral coefficients on sigma levels.

Determination of the wave parameters at a given time $t$, latitude $y$, and isentropic level $\theta$ is accomplished by the following procedure. Given two fields $f(x, y, \theta, t)$ and $g(x, y, \theta, t)$, we can calculate various correlations at time $t$ along latitude $y$ as

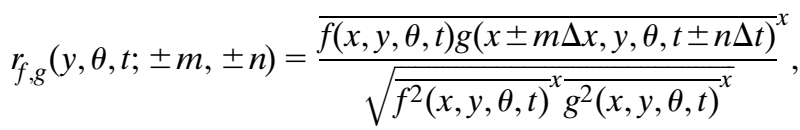

where $\Delta x$ is the grid size in longitude $\left(2.5^{\circ}\right)$ and $\Delta t=1$ day, the time interval of the daily data; $m$ and $n$ are positive integers; and the overbar with superscript $x$ denotes an averaging over $x$ covering the entire latitude circle at $y$ on isentropic surface $\theta$.

We infer the amplitude-weighted "effective wavenumber," "effective phase speed," and "effective vertical tilting" of wavelike disturbances at $(y, \theta, t)$ by applying $r_{f, g}(y, \theta, t ; m, n)$ to $z$ and $T$ fields; namely,

$$
\begin{aligned}
k_{\text {effective }}(y, \theta, t) & =\frac{\arccos \left[r_{z, z}(y, \theta, t ; 1,0)\right]}{\Delta x}=\frac{\arccos \left[r_{z, z}(y, \theta, t ;-1,0)\right]}{\Delta x} \\
c_{\text {effective }} & \left.=\frac{\arcsin \left[\frac{r_{z, z}(y, \theta, t ; 1,1)+r_{z, z}(y, \theta, t ;-1,-1)-r_{z, z}(y, \theta, t ;-1,1)-r_{z, z}(y, \theta, t ; 1,-1)}{4 \sin \left(k_{\text {effective }} \Delta x\right)}\right]}{k_{\text {effective }} \Delta t}\right] \\
\phi_{\text {effective }}(y, \theta, t) & =\arcsin \left[\frac{r_{z, T}(y, \theta, t ; 1,0)-r_{z, T}(y, \theta, t ;-1,0)}{2 \sin \left(k_{\text {effective }} \Delta x\right)}\right] .
\end{aligned}
$$


Positive values of $\phi_{\text {effective }}$ correspond to vertically eastward-tilted waves [or temperature troughs (ridges) on the eastern side of geopotential height troughs (ridges)] and negative values indicate westward tilting. The derivation of (2) is based on the situation of a single monotonic wave of $z$ and $T$ with constant amplitude: $z(x, t)=A \cos [k(x-c t)]$ and $T(x, t)=B \cos [k(x-c t)$ $\left.-\phi_{0}\right]$. One can easily verify that for the case of a monotonic wave, we have $k_{\text {effective }}=k, c_{\text {effective }}=c$, and $\phi_{\text {effective }}=\phi_{0}$ exactly. The results presented in the online supplement confirm that $k_{\text {effective }}, c_{\text {effective }}$, and $\phi_{\text {effective }}$ evaluated from (2) mainly represent the amplitudeweighted averages of $k, c$, and vertical tilting for situations of the presence of more than one wave. Also the physical meaning of (2) is provided there.

We have also calculated the so-called form stress or the pressure torque of the air mass above exerted on the air mass below via sloped isentropic surfaces (e.g., Tung 1982; Andrews 1983; Johnson 1989). At the equator, it is defined as

$$
\left.T^{\mathrm{pres}}\right|_{\theta}=\int_{0}^{2 \pi}\left(-p \frac{\partial z}{\partial \lambda}\right)_{\theta} a^{2} d \lambda,
$$

where $a$ is Earth's radius and $\lambda$ is longitude in radians. The subscript $\theta$ means that the integral is taken along an isentropic surface. Positive $\left.T^{\text {pres }}\right|_{\theta}$ corresponds to a gain of westerly angular momentum in the layer above $\theta$ and a loss in the layer below $\theta$ due to the pressure torque exerted on $\theta$. In the interior atmosphere, the pressure torque is associated with vertically tilted waves (e.g., Johnson 1989). Under hydrostatic balance, air in the layer above $\theta$ exerts an eastward torque to air below if the longitudinally sloped isentropic interfaces tilt westward with height. Therefore, westward-tilted waves $\left(\phi_{\text {effective }}>0\right)$ act to transfer westerly angular momentum downward and vice versa. As shown in section 3, the wave tilting evaluated using (2) is positively correlated with the independently calculated form-stress results using (3), which further confirms that the spatial-temporal correlation method [i.e., (1)-(3)] does yield valuable information about the temporal evolution of the wave properties.

By applying (2)-(3) to the total fields of $z, T$, and $p$ at the equator $(y=0)$, we have obtained four daily time series $\left(2 \pi / k_{\text {effective, }} c_{\text {effective }}, \phi_{\text {effective, }}\right.$ and $\left.\left.T^{\text {pres }}\right|_{\theta}\right)$ on each of the six isentropic surfaces covering the entire 32-yr period. Although the dominance of the QBO time scale can be identified from these raw daily time series (not shown here), we have applied a low-pass filter to these raw time series by filtering out signals with time scale less than 1 year with both the annual cycle and the longtime mean retained. From the low-pass-filtered time series, we can examine more closely how these wave properties change with respect to the background QBO in the zonal-mean zonal wind field $[u]$. Note that $c_{\text {effective }}$ defined in (2) is the phase speed relative to the ground. The intrinsic phase speed of waves, or the non-Dopplershifting part, which is the part of the phase speed that is due to the restoring force on wave motions, can be inferred from $c_{\text {effective according to }}$

$$
c_{\text {intrinsic }}=-[u]+c_{\text {effective }} \text {. }
$$

\section{Results}

The time series of $c_{\text {effective }}$ (Fig. 1) reveals that the waves in the equatorial stratosphere tend to be dominated by waves that propagate very slowly relative to the ground. Although there exist some pronounced shorttime-scale variations (gray curves), the amplitudeweighted effective phase speed has a noticeable QBO signal. The slowness of the effective phase speed implies that $c_{\text {intrinsic }}$ is always in the opposite direction of the background zonal flow, as implied by the wave-mean interaction theory for the QBO. This is another way of showing the well-known observational fact that only westward-propagating waves are present in the westerly phase of the QBO and only eastward-propagating waves in the easterly phase. It is also seen that the effective phase speed follows the QBO in such a way that it is fastest at the end of the easterly phase and slowest at the end of the westerly phase, suggestive of a lag of the directional change of $c_{\text {intrinsic }}$ with respect to the QBO phase change. Therefore, the change of the dominant wave types from westward- to eastward-propagating waves tends to lag the change of the QBO phase. Similar to the background QBO signal, $c_{\text {effective }}$ also has a pronounced downward-propagation signal. Figure 2 shows that the amplitude-weighted effective wavelength, equaling $2 \pi / k_{\text {effective, }}$, varies between 3000 and $5000 \mathrm{~km}$ with a noticeable QBO signal.

The vertical tilting of equatorial waves in the stratosphere has a pronounced QBO signal with very weak short-time-scale variations and little amplitude in the annual cycle (Fig. 3) -namely, westward-tilted waves in a westerly phase and eastward-tilting waves in an easterly phase of the QBO. The QBO signal in the waves' vertical structure is expected from the changes in the dominant waves originating from the troposphere. In other words, to have upward energy propagation (which is along constant-phase surfaces of gravity waves), westward-propagating waves have to tilt westward and eastward-propagating waves tilt eastward. The oscillation between westward- and eastward-tilted waves 


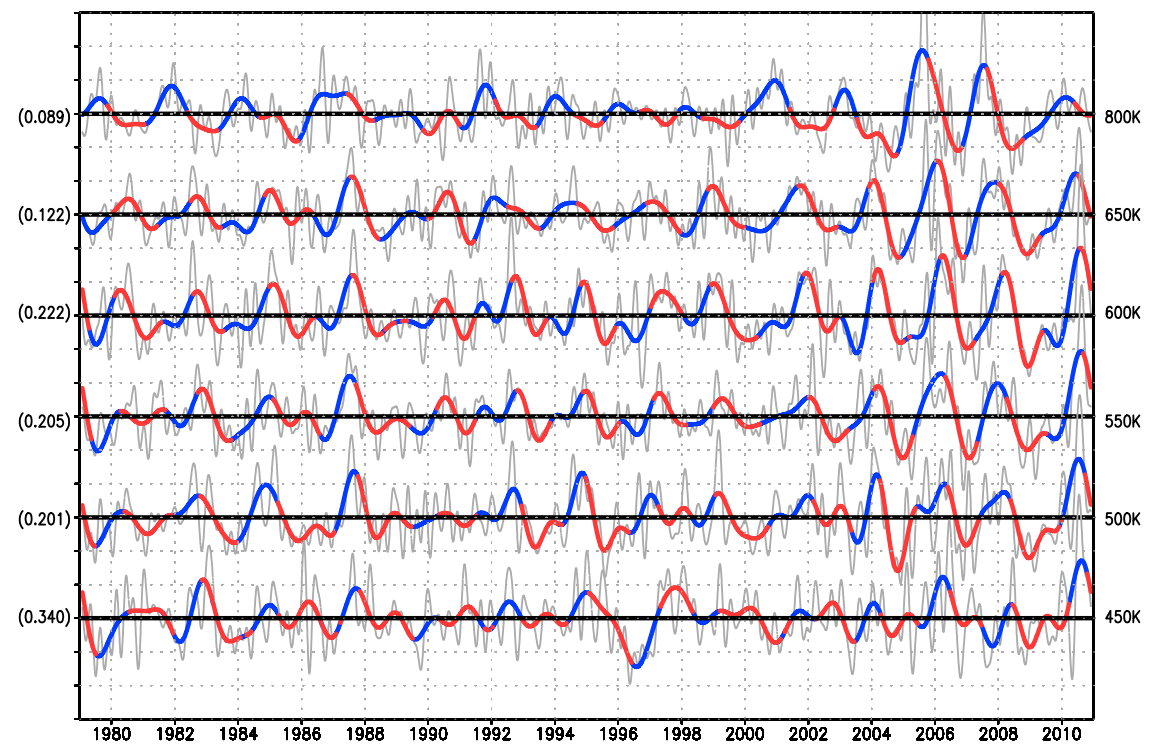

FIG. 1. Time series of bandpass-filtered $c_{\text {effective }}$ of waves (gray curves are 3 months- 5 years and color curves are 1-5 years) at isentropic levels (from top to bottom) 800, 650, 600, 550, 500, and $450 \mathrm{~K}$. Note that the time mean and annual cycle have not been removed. Blue (red) portions of each color curve indicate times when the background flow at that level is easterly (westerly). To illustrate downward propagation clearly, the six series are plotted on the same ordinate axis. Each time series is centered at its individual time mean (black horizontal line), which is given on the left axis $\left(\mathrm{m} \mathrm{s}^{-1}\right)$. Each tick mark on the ordinate above (below) one of the six horizontal axes represents an increment (decrement) of $0.2 \mathrm{~m} \mathrm{~s}^{-1}$ from the corresponding reference value marked on the left.

implies that eastward and westward (gravity) waves alternate dominance as the local QBO phase alternates, which again agrees with Lindzen and Holton (1968).
Such a QBO signal in the waves' vertical structure immediately implies an oscillation between the downward transfer of westerly angular momentum $\left(\left.T^{\text {pres }}\right|_{\theta}<0\right)$ in the westerly phase of the QBO and the downward transfer

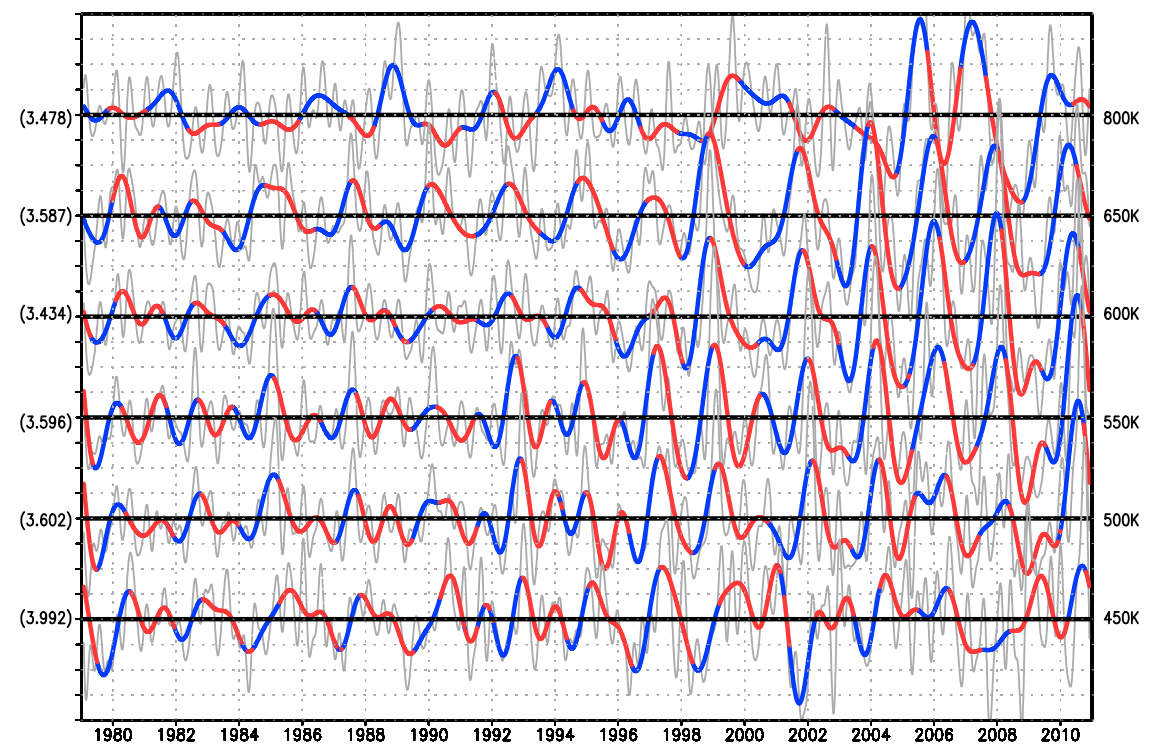

FIG. 2. As in Fig. 1, but for amplitude-weighted effective wavelength $\left(L_{\text {effective }}=2 \pi / k_{\text {effective }}\right)$ of waves. Each tick mark represents an increment or decrement of 0.25 (no dimension) from the corresponding reference value marked on the left. To obtain the original values of $L_{\text {effective }}$ in kilometers, one needs to multiply the curve values by 1000 . 


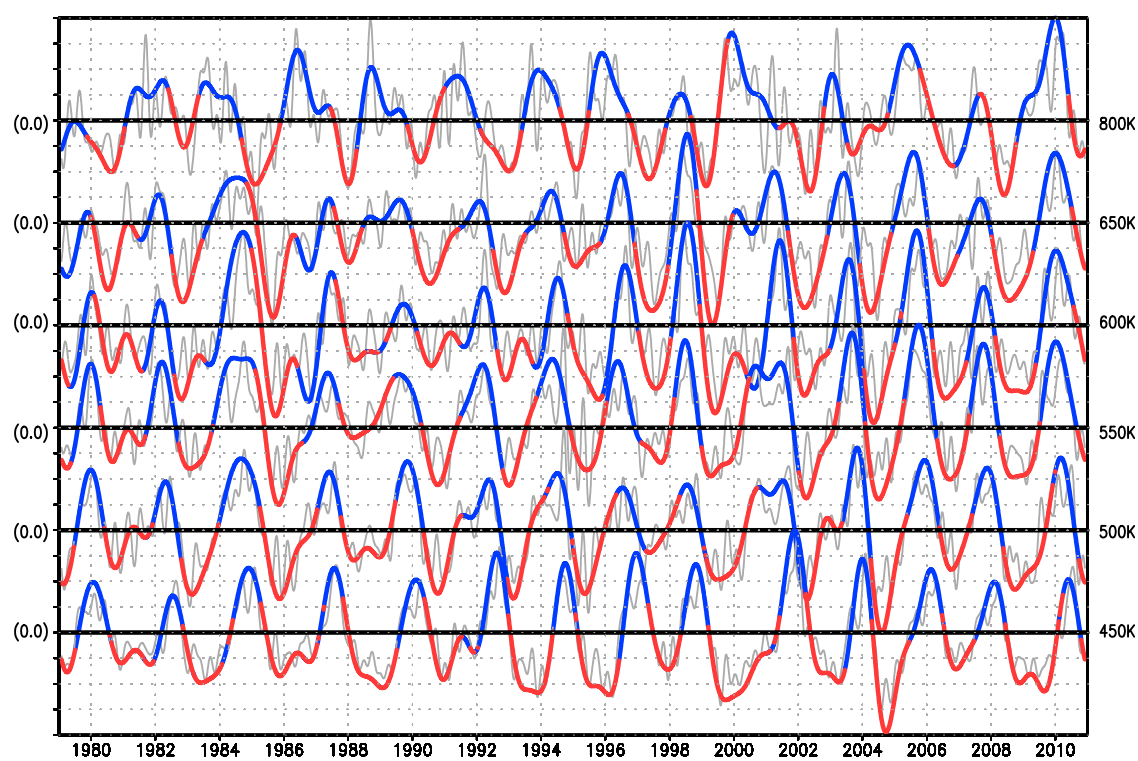

FIG. 3. As in Fig. 1, but for the vertical tilting $\phi_{0}$ of waves. For clarity, each time series of $\phi_{0}$ is normalized by its maximum (absolute) value. Each tick mark represents an increment or decrement of 0.25 (no dimension) from the reference value, which is zero. To obtain the original values of $\phi_{0}$ in radians (in kilometers), one needs to multiply the curve values by 0.0139 (88.5) for the time series at $800 \mathrm{~K}, 0.0137(87.3)$ at $650 \mathrm{~K}, 0.00928(59.11)$ at $600 \mathrm{~K}, 0.0118$ (75.17) at $550 \mathrm{~K}, 0.0149(94.91)$ at $500 \mathrm{~K}$, and $0.0180(114.66)$ at $450 \mathrm{~K}$.

of easterly angular momentum $\left(\left.T^{\text {pres }}\right|_{\theta}>0\right)$ in the easterly phase, as shown in Fig. 4. Therefore, the dominance of eastward-propagating waves in the easterly phase of the QBO contributes to an acceleration of westerly (easterly) flow in the upper (low) level that acts to reverse the easterly flow to westerly in the upper level and cause a downward propagation of easterly flow signal. Similarly, the dominance of westward-propagating

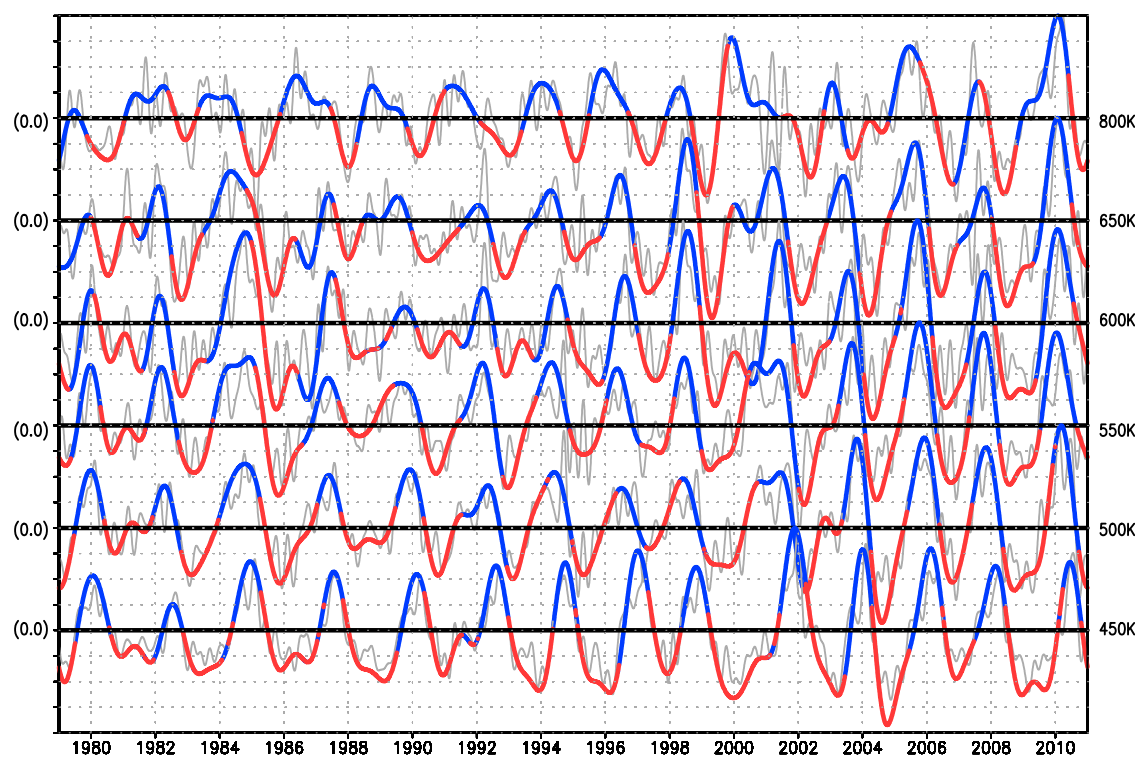

FIG. 4. As in Fig. 3, but for the form stress. To obtain dimensional values of the form stress in units of hadleys $\left(10^{18}\right.$ Joule), one needs to multiply the curve values by 0.00491 for the time series at $800 \mathrm{~K}, 0.00708$ at $650 \mathrm{~K}, 0.00922$ at $600 \mathrm{~K}, 0.0111$ at $550 \mathrm{~K}, 0.0163$ at $500 \mathrm{~K}$, and 0.0279 at $450 \mathrm{~K}$. 


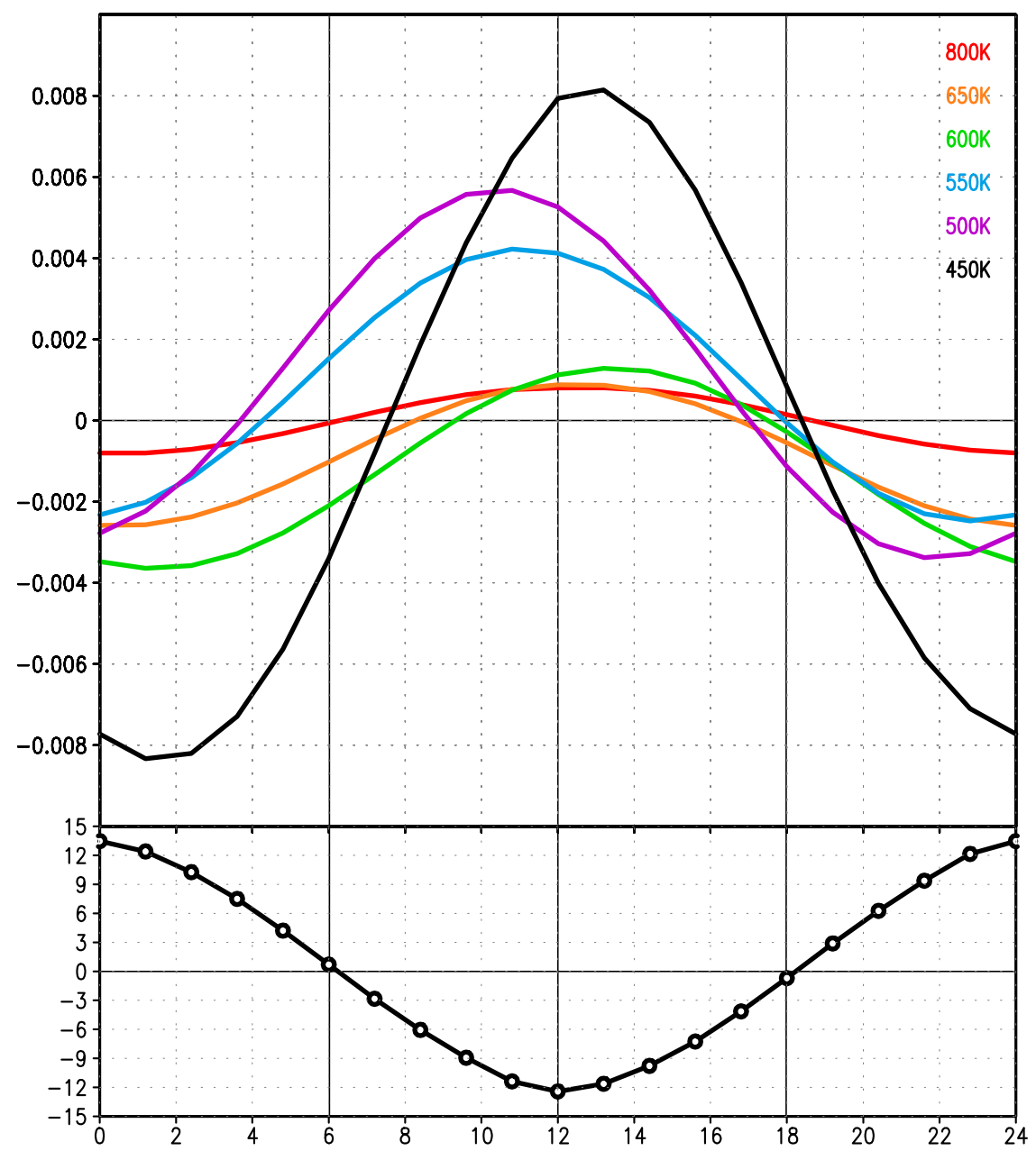

FIG. 5. (top) Composite time series of the form stress (hadleys; 1 hadley $=10^{18} \mathrm{~kg} \mathrm{~m}^{2} \mathrm{~s}^{-2}$ ) at all levels that have been synchronized according to the local phase (abscissa) of the composite QBO signal of the background zonal wind at that level. (bottom) Composite QBO in $[u]$ at $650 \mathrm{~K}$ as an example of the synchronized QBO evolution.

waves in the westerly phase of the QBO acts to cause a reversal from westerly flow to easterly flow and a downward propagation of westerly flow signal.

The downward propagation of both the background zonal-mean zonal wind and the form stress (as well as other properties of the dominant waves) suggests that the temporal evolution of the form stress is intimately coupled with the QBO signal at each level. To highlight this, in Fig. 5 we plot the composite time series of the form stress at each level as a function of the phase of the composite QBO signal at that level (referred to as the local QBO phase). The local QBO phase runs from 0 to 24, covering the whole QBO cycle with the peak of the westerly regime at phase 0 , the transition from the westerly to the easterly regime at phase 6 , the peak of the easterly regime at phase 12 , the transition from the easterly to the westerly regime at phase 18 , and the peak of the westerly regime again at phase 24 , respectively. It is seen that the form stress is nearly $180^{\circ}$ out of phase with the background QBO cycle, showing downward transfer of westerly angular momentum in the westerly regime and easterly angular momentum in the easterly regime. Therefore, the form stress associated with the equatorial stratospheric waves always has two direct effects on the background flow: (i) causing a reversal of the background flow at the same level and (ii) transferring angular momentum anomalies of the same sign to the level below. Another interesting feature is that in most levels except 500 and $550 \mathrm{~K}$, the downward transfer of westerly angular momentum has larger amplitude and lasts longer (more than a half period of the QBO cycle) than that of easterly angular momentum. This seems to partially explain why the downward propagation of westerly regime is faster than easterly regime shown in observations (Andrews et al. 1987). 


\section{Summary}

In this study, the continuous evolution of equatorial wave parameters and the background QBO has been demonstrated using a novel diagnostic technique based on the local autocorrelation. We have diagnosed the amplitude-weighted effective phase speed and vertical tilting of equatorial waves in the stratosphere as well as their associated form stress (or pressure torque) on a daily basis using the NCEP-DOE reanalysis for the period from 1 January 1979 to 31 December 2010. Most of the properties of the temporally continuous evolution of the dominant wave regime are consistent with established QBO theory; however, the analysis also indicates the potential role of wave-induced form stress in driving the QBO regime change.

Our results show that all of the wave properties follow the equatorial stratospheric QBO of zonal wind very closely with a downward-propagation signal. Specifically, the dominant waves in the equatorial stratosphere propagate very slowly relative to the ground all the time. The slowness of the ground-relative phase speed implies that the intrinsic phase speed of the dominant waves (without the Doppler shift) in the equatorial stratosphere is always in the opposite direction of the background flow. Both the vertical tilting and form stress have a very pronounced QBO signal. The QBO signal of these properties of the dominant waves in the equatorial stratosphere further directly confirms the wave regime alternation from the dominance of westward-tilted, westward-propagating waves in the westerly phase of the QBO to the dominance of eastward-tilted, eastwardpropagating waves in the easterly phase of the QBO. Such alternation of the vertical tilting of the dominant waves at the QBO time scale is indicative of upward energy propagation of these waves at all times. This indicates that the dominant waves in the equatorial stratosphere are originated from the troposphere throughout the entire cycle of the QBO, as expected. The alternation of the dominant wave regimes between the westerly and easterly phases of the QBO also implies a $Q B O$ variation of the form stress associated with these vertically tilted waves before their amplitude is damped (owing to radiative-mechanic damping or critical-level absorption). The dominance of eastward-tilted, eastward-propagating waves in the easterly phase of the QBO contributes to a deceleration of easterly flow in the upper levels and causes a downward propagation of easterly flow signal and vice versa in the westerly phase of the QBO. In light of this, we conclude that in addition to the wave-breaking processes, such continuously alternating downward transfer of westerly and easterly angular momentum by westward-tilted, westward-propagating waves and eastward-tilted, eastward-propagating waves contributes to the wave-mean flow interaction mechanism for the QBO.

Despite advances in theory, the accurate representation of the QBO has eluded most general circulation models. There are many possible reasons for this, including the role of unresolved waves as a likely culprit. In addition to highlighting the importance of waveinduced form stress, the diagnostic approach presented in this paper offers a convenient means of evaluating the characteristics of wave-mean flow interaction in GCMs as well as observations. Although the technique may not directly reveal the role of the unresolved waves, it may nevertheless shed light on deficiencies concerning resolved wave-mean flow interaction in models. As the resolution of GCMs becomes increasingly finer, this type of analysis will become an essential step in evaluating simulated QBO dynamics.

Acknowledgments. This research was in part supported by research grants from Chinese Ministry of Science and Technology (2010CB951600), National Science Foundation (ATM-0833001), the NOAA CPO/ CPPA program (NA10OAR4310168), the DOE Office of Science Regional and Global Climate Modeling program (DE-SC0004974), and the NASA Living With a Star Program (NNX13AF91G).

\section{REFERENCES}

Alexander, S. P., T. Tsuda, Y. Kawatani, and M. Takahashi, 2008: Global distribution of atmospheric wave in the equatorial upper troposphere and lower stratosphere: COSMIC observations of wave mean flow interactions. J. Geophys. Res., 113, D24115, doi:10.1029/2008JD010039.

Andrews, D. G., 1983: A finite-amplitude Eliassen-Palm theorem in isentropic coordinates. J. Atmos. Sci., 40, 1877-1883, doi:10.1175/1520-0469(1983)040<1877:AFAEPT>2.0.CO;2.

_ Dynamics. Academic Press, 489 pp.

Baldwin, M. P., and Coauthors, 2001: The quasi-biennial oscillation. Rev. Geophys., 39, 179-229, doi:10.1029/1999RG000073.

Dunkerton, T. J., 1997: The role of gravity waves in the quasibiennial oscillation. J. Geophys. Res., 102, 26053-26076, doi:10.1029/96JD02999.

Ern, M., and P. Preusse, 2009: Wave fluxes of equatorial Kelvin waves and QBO zonal wind forcing derived from SABER and ECMWF temperature space-time spectra. Atmos. Chem. Phys., 9, 3957-3986, doi:10.5194/acp-9-3957-2009.

,, M. Krebsbach, M. G. Mlynczak, and J. M. Russell III, 2008: Equatorial wave analysis from SABER and ECMWF temperatures. Atmos. Chem. Phys., 8, 845-869, doi:10.5194/ acp-8-845-2008.

- and Coauthors, 2014: Interaction of gravity waves with the QBO: A satellite perspective. J. Geophys. Res., 119, 23292355, doi:10.1002/2013JD020731. 
Giorgetta, M. A., E. Manzini, and E. Roeckner, 2002: Forcing of the quasi-biennial oscillation from a broad spectrum of atmospheric waves. Geophys. Res. Lett., 29, 1245, doi:10.1029/ 2002GL014756.

,,,--- M. Esch, and L. Bengtsson, 2006: Climatology and forcing of the quasi-biennial oscillation in the MAECHAM5 model. J. Climate, 19, 3882-3901, doi:10.1175/JCLI3830.1.

Holton, J. R., and R. S. Lindzen, 1972: An updated theory for the quasi-biennial oscillation of the tropical stratosphere. J. Atmos. Sci., 29, 1076-1080, doi:10.1175/1520-0469(1972)029<1076: AUTFTQ $>2.0 . \mathrm{CO} ; 2$.

Johnson, D. R., 1989: The forcing and maintenance of global monsoonal circulation: An isentropic analysis. Advances in Geophysics, Vol. 31, 43-316, doi:10.1016/S0065-2687(08)60053-9.

Kanamitsu, M., W. Ebisuzaki, J. Woollen, S.-K. Yang, J. J. Hnilo, M. Fiorino, and G. L. Potter, 2002: NCEP-DOE AMIP-II reanalysis (R-2). Bull. Amer. Meteor. Soc., 83, 1631-1644, doi:10.1175/BAMS-83-11-1631.

Lindzen, R. S., and J. R. Holton, 1968: A theory of the quasibiennial oscillation. J. Atmos. Sci., 25, 1095-1107, doi:10.1175/ 1520-0469(1968)025<1095:ATOTQB > 2.0.CO;2.

—_, and C.-Y. Tsay, 1975: Wave structure of the tropical stratosphere over the Marshall Islands area during 1 April-1 July 1958. J. Atmos. Sci., 32, 2008-2021, doi:10.1175/ 1520-0469(1975)032<2008:WSOTTS >2.0.CO;2.

Plumb, R. A., and A. D. McEwan, 1978: The instability of a forced standing wave in a viscous stratified fluid: A laboratory analogue of the quasi-biennial oscillation. J. Atmos. Sci., 35, 1827-1839, doi:10.1175/1520-0469(1978)035<1827: TIOAFS $>2.0 . \mathrm{CO} ; 2$.
Reed, R. J., W. J. Campbell, L. A. Rasmussen, and R. G. Rogers, 1961: Evidence of a downward propagating annual wind reversal in the equatorial stratosphere. J. Geophys. Res., 66, 813818, doi:10.1029/JZ066i003p00813.

Tindall, J. C., J. Thuburn, and E. J. Highwood, 2006a: Equatorial waves in the lower stratosphere. I: A novel detection method. Quart. J. Roy. Meteor. Soc., 132, 195-212, doi:10.1256/ qj. 04.153 .

,-- , and,$- 2006 \mathrm{~b}$ : Equatorial waves in the lower stratosphere. II: Annual and interannual variability. Quart. J. Roy. Meteor. Soc., 132, 195-212, doi:10.1256/qj.04.153.

Tung, K. K., 1982: On the two-dimensional transport of stratospheric trace gases in isentropic coordinates. J. Atmos. Sci., 39, 2330-2355, doi:10.1175/1520-0469(1982)039<2330: OTTDTO $>2.0 . \mathrm{CO} ; 2$.

Veryard, R. G., and R. A. Ebdon, 1961: Fluctuations in tropical stratospheric winds. Meteor. Mag., 90, 125-143.

Wallace, J. M., and V. E. Kousky, 1968a: Observation evidence of Kelvin waves in the tropical stratosphere. J. Atmos. Sci., 25, 900-907, doi:10.1175/1520-0469(1968)025<0900: OEOKWI>2.0.CO;2.

$\longrightarrow$, and $-1968 \mathrm{~b}$ : On the relation between Kelvin waves and the quasi-biennial oscillation. J. Meteor. Soc. Japan, 46, 496502 .

Yanai, M., and T. Maruyama, 1966: Stratospheric wave disturbances propagating over the equatorial Pacific. J. Meteor. Soc. Japan, 44, 291-294.

Yang, G.-Y., B. J. Hoskins, and J. M. Slingo, 2011: Equatorial waves in opposite QBO phases. J. Atmos. Sci., 68, 839-862, doi:10.1175/2010JAS3514.1. 